\title{
WP 08_10
}

\author{
Massimiliano Marzo
}

Department of Economics, Università di Bologna and Rimini Centre for Economic Analysis (RCEA)

Paolo Zagaglia

Department of Economics, Università di Bologna and Rimini Centre for Economic Analysis (RCEA)

\section{GOLD AND THE U.S. DOLLAR: TALES FROM THE TURMOIL}

Copyright belongs to the author. Small sections of the text, not exceeding three paragraphs, can be used provided proper acknowledgement is given.

The Rimini Centre for Economic Analysis (RCEA) was established in March 2007. RCEA is a private, nonprofit organization dedicated to independent research in Applied and Theoretical Economics and related fields. RCEA organizes seminars and workshops, sponsors a general interest journal The Review of Economic Analysis, and organizes a biennial conference: The Rimini Conference in Economics and Finance (RCEF) . The RCEA has a Canadian branch: The Rimini Centre for Economic Analysis in Canada (RCEACanada). Scientific work contributed by the RCEA Scholars is published in the RCEA Working Papers and Professional Report series.

The views expressed in this paper are those of the authors. No responsibility for them should be attributed to the Rimini Centre for Economic Analysis. 


\title{
Gold and the U.S. Dollar: Tales from the Turmoil
}

\author{
Massimiliano Marzo and Paolo Zagaglia*
}

This version: April 26, 2010

\begin{abstract}
We investigate how the relation between gold prices and the U.S. Dollar has been affected by the recent turmoil in financial markets. We use spot prices of gold and spot bilateral exchange rates against the Euro and the British Pound to study the pattern of volatility spillovers. We estimate the bivariate structural GARCH models proposed by Spargoli e Zagaglia (2008) to gauge the causal relations between volatility changes in the two assets. We also apply the tests for change of co-dependence of Cappiello, Gerard and Manganelli (2005). We document the ability of gold to generate stable comovements with the Dollar exchange rate that have survived the recent phases of market disruption. Our findings also show that exogenous increases in market uncertainty have tended to produce reactions of gold prices that are more stable than those of the U.S. Dollar.
\end{abstract}

Keywords: gold, exchange rates; GARCH, quantile regressions.

JEL Classification: C22, F31, F33.

${ }^{*}$ Marzo: Department of Economics, Università di Bologna and Rimini Centre for Economic Analysis (RCEA); massimiliano.marzo@unibo.it. Zagaglia: Department of Economics, Università di Bologna and Rimini Centre for Economic Analysis (RCEA); paolo.zagaglia@gmail.com. This research was carried out by the authors for purely academic purposes and without financial support from any private institution. 
"(Gold's) quantity cannot increase at the same rate as you can print money, which will eventually weaken the US dollar," Faber said on Thursday in a live interview.

Marc Faber on CNBC, March 42010

"There is still a link on a day-to-day and weekly basis between gold and the dollar, so if the euro weakens gold will come under pressure," said Standard Bank analyst Walter de Wet. "We might test down towards $1.10 \$$ if the euro goes to $1.30 \$ . "$

CNBC Commentary, March 42010

\section{Introduction}

Various accounts of the recent financial turmoil have stressed the propensity of investors to turn away from risky securities into 'safe' assets. This flight to safety has also taken the form of a renowned interest in gold as an asset class. In fact, it is typically argued that the price of this precious metal is uncorrelated with both stock and bond prices during episodes of market crash. Gold is also identified as a hedge against fluctuations in the U.S. Dollar on average, both in distressed and in normal market conditions (see Baur and Lucey, 2010; Baur and McDermott, 2010). ${ }^{1}$ The properties of safe asset and hedging capabilities suggest that the dollar price of gold should increase when the bilateral exchange of the U.S. Dollar against other currencies depreciates.

The international role of the gold dates back to the early years of the Nineteenth century when several countries adopted the 'gold standard'. In this arrangement, the value of the currency was backed by government holdings of gold. The gold standard collapsed in 1971 with the decision of President Richard Nixon to end the Dollar convertibility into gold.

Cappie, Mills and Wood (2005) point out that two reasons are typically suggested for the use of gold as a hedging instrument or safe asset against exchange rate risk. First, a number of financial products are available that track the price of gold, despite the fact that they do not involve the property of the physical commodity. For instance there are commodity Exchange Traded Funds that are linked to gold. Second, gold is often pointed at as a protection against currency fluctuations worldwide, not only for the U.S. Dollar (Sjaastad and Scacciavillani, 1996, see also). The results of Cappie, Mills and Wood (2005) show that the hedging power of gold for the U.S. Dollar has varied widely since 1971. In particular, they argue that the degree of protection offered by the Dollar depends on largely unpredictable events. ${ }^{2}$

In this paper we study how the relation between gold prices and the U.S. Dollar has been affected by the turmoil that erupted in financial markets in 2007. The available literature on

\footnotetext{
${ }^{1}$ Several contributions indicate that gold provides stability to industry portfolios. For instance, Davidson, Faff and Hillier (2003) show that standard international asset pricing models prescribe a systematic exposure to gold.

${ }^{2}$ We should stress that the price of gold is also affected by some of the driving factors of the Dollar exchange rate, such as inflation expectations (see Blose, 2010) and the release of macroeconomic news (see Christie-David, Chaudhry and Koch, 2000).
} 
gold as hedging asset or safe haven typically focuses on the pattern of correlation. A negative (conditional or unconditional) correlation is indicative of hedging capabilities. We consider a more general approach, and shed light on properties of the relation between gold and the Dollar that have not been considered previously. In particular, we study the evolution of the pattern of contagion between the two assets across the turmoil.

Our investigation employs two econometric framework to evaluate the change in the comovements between gold and the U.S. Dollar. First, we provide evidence on the how the impact of volatility shocks and spillovers has changed during the turmoil. We estimate the standard bivariate GARCH models proposed by Engle and Kroner (1995). In order to uncover the role played by market linkages in the propagation of volatility shocks, we consider the extension to the structural BEKK model discussed in Spargoli e Zagaglia (2008). This amounts to using the information from time-varying conditional heteroskedasticity to identify causal relations between the volatility movements in the price of gold and the U.S. Dollar (see Rigobon, 2003).

In the following step, we study how the tail behavior of the two assets has changed during the turmoil. We focus on the evolution of comovements between extreme prices. We use the measure of contagion proposed by Cappiello, Gerard and Manganelli (2005) to investigate whether the probability of observing closer comovements has increased since August 2007. The framework of Cappiello, Gerard and Manganelli (2005) is based on the computation of the probability of a variable falling below a threshold conditional on the same pattern for the other variable. Thresholds are obtained through quantile estimation. In this statistical model, a high conditional probability of comovement implies a strong co-dependence between the variables.

We uncover a feature of gold that is typically disregarded. This consists in its ability to generate stable comovements with the U.S. Dollar exchange rate that survive in phases of market disruption. Our findings also show that exogenous increase in market uncertainty have tended to produce reactions of gold prices that are more stable than those of the U.S. Dollar.

This paper is organized as follows. Section 2 presents the dataset and discusses some properties of the series. Section 3 elaborates on a structural BEKK model to provide an interpretation of the effects of volatility changes. In section 4 we focus on the relationship at the tails of the distributions, and present evidence of comovement patterns of extreme price changes based on quantile regressions. Section 5 concludes the paper. 


\section{The dataset}

In this paper we use daily data for spot contracts of exchange rates between the U.S. Dollar and the Euro and the U.S. Dollar and the British Pound. Our dataset also includes settlement prices for spot contracts of gold negotiated in the Chicago Board of Trade, expressed in U.S. dollars for 100 ounces. Both the exchange rate and gold price data were extracted from Datastream. The dataset spans from October 132004 to March 5 2010. We consider August 92007 as the starting date for the outbreak of the turmoil in worldwide financial markets. During that day, BNP Paribas froze the redemption of three investment funds, and the resulting panic forced the the European Central Bank to start extrordinary measures for the supply of liquidity in the Euro interbank market.

Figure 1 plots the data series (in logarithm), and Table 1 reports some descriptive statistics. During the turmoil, the U.S. Dollar depreciates, on average, with respect to the Euro, and appreciates with respect to the British Pound. The average price of the gold also increases. The gold price becomes more stable during the turmoil, as it displays a lower standard deviation during the turmoil period. This is however not the case for the exchange rates, that are characterized by more extreme movements.

It is also instructive to consider the two scatter plots of the (logs) bilateral exchange rates against the price of gold. Figure 2 includes the plots with a distinction for the periods before and during the turmoil. The USD/EUR exhibits a positive correlation with price of gold both before and during the turmoil. This can be interpreted as evidence suggesting that investors have used gold as a hedge for the USD/EUR exchange rate. For the USD/GBP exchange rate instead, the turmoil appears to be characterized by a break in the correlation with the price of gold. The turmoil apparently has induced investors to hold gold for hedging purposes also against a fall of the USD/GBP exchange rate.

\section{Some structural evidence on volatility spillovers}

In order to understand how the hedging power of the gold is changed during the turmoil, we investigate how the pattern of transmission of shocks with the U.S. Dollar has evolved. For that purpose, we estimate the structural BEKK model discussed in Spargoli e Zagaglia (2008).

We assume that the joint evolution of a bilateral USD exchange rate return and gold returns can be summarized by a structural vector-autoregressive (VAR) model

$$
A x_{t}=\Psi+\Phi(L) x_{t}+\eta_{t}
$$

where $x_{t}$ is the vector of the vector of returns, $\Psi$ is a vector of constants, $A$ is a matrix of structural parameter, and $\eta_{t} N\left(0, h_{t}\right)$ is a vector of structural shocks. The structural innovations exhibit conditional heteroskedasticity. We use the BEKK-GARCH model of Engle 
and Kroner (1995)

$$
h_{t}=C C^{\prime}+G h_{t-1} G^{\prime}+T \eta_{t-1} \eta_{t-1}^{\prime} T^{\prime}
$$

In the model 1-2, the regressors are not exogenous because their source of variation is represented by the dependent variable in the same equation through another equation in the system. In order to achieve identification of the relations modelled in the VAR we rely on heteroskedasticity. This idea has been originally introduced by Wright (1928) and recently developed by Rigobon (2003). The heteroskedasticity approach to identification amounts to using the information from time-varying volatility as a source of exogenous variation in the endogenous variables. To see this, let us consider the reduced-form VAR model

$$
x_{t}=c+F(L) x_{t}+v_{t}
$$

where $c=A^{-1} \Psi, F(L)=A^{-1} \Phi(L)$ and $v_{t}=A^{-1} \eta_{t}$ are the reduced-form innovations, whose variance-covariance matrix is a combination of the variance-covariance matrix of the structural-form innovations, that is

$$
\begin{aligned}
& H_{t}=B h_{t} B^{\prime} \\
& H_{t}=B C C B^{\prime}+B G h_{t-1} G^{\prime} B^{\prime}+B T \eta_{t-1} \eta_{t-1}^{\prime} T^{\prime} B^{\prime}
\end{aligned}
$$

In this formulation the variance-covariance matrix of the reduced-form innovations is a function of the structural innovations, which the econometrician does not know. However, we can use the equality to show that

$$
\eta \eta^{\prime}=A v_{t} v_{t}^{\prime} A^{\prime}
$$

and to represent in terms of the reduced-form innovations as

$$
H_{t}=B C C B^{\prime}+B G A H_{t-1} A^{\prime} G^{\prime} B^{\prime}+B T A v_{t-1} v_{t-1}^{\prime} A^{\prime} T^{\prime} B^{\prime} .
$$

This reduced form is then used for the estimation.

After estimating the model, we compute impulse-response functions. In structural GARCH models, these functions show the impact that a shock produces on the conditional second moments of the variables in the system. However, differently from the impulse response functions for a standard VAR, the impulse responses of a structural GARCH depend both on the magnitude of the shock and on the period during which the shock itself takes place. This is due to the fact that the residuals enter the model in quadratic form. Hence, differently from the case of linear models, the magnitude of the effects of a shock is not proportional to the size of the shock itself. This allows us to compute a distribution of impulse responses following each shock. For this purpose, we use the concept of Volatility Impulse Response 
Functions (VIRF) proposed by Hafner and Herwartz (2006). The impulse-response function for a vech-GARCH model can be written as

$$
V_{t}\left(\xi_{0}\right)=\mathrm{E}\left(\operatorname{vech}\left(H_{t}\right) \mid \xi_{0}, I_{t-1}\right)-\mathrm{E}\left(\operatorname{vech}\left(H_{t}\right) \mid I_{t}\right)
$$

The response at time $\mathrm{t}$ of the variances and covariances following a shock $\eta_{t}$ in $\mathrm{t}=0$, denoted as $V_{t}\left(\xi_{0}\right)$, is equal to the difference, conditioned on the information set $I_{t-1}$ at time -1 and on the shock $\eta_{0}$, of the variance (or covariance) at $\mathrm{t}$ from its expected value conditional on the information set of the previous period.

We have used standard likelihood methods to estimate two structural BEKK models with the returns of each bilateral exchange rate and gold. The parameter estimates are listed in Table 2. The standard errors are computed using the delta method like in Spargoli e Zagaglia (2008). It should be stressed that all the estimated parameters are statistically significant at standard confidence levels. Figure 3 reports the conditional variances of both the structural BEKK model, as well as the variances from a reduced-form model that disregards the issue of identification of causal relations. Two observations emerge. The first one is that the outbreak of the turmoil per se has not enhanced the pattern of uncertainty for the returns of either gold, or the bilateral exchange rates. Rather, there is a surge in volatility in correspondence with the bankruptcy of Lehman Brothers of September 15 2008. The second point is that the reduced-form estimates lay on top of the structural variances. This suggests that the links between the gold and the foreign exchange markets exacerbate the transmission of shocks and, thus, the uncertainty in the price movements.

Figure 4 plots the structural and reduced-form estimates of the correlations. The turmoil has no clear-cut effect on the dynamics of the correlations. On the other hand, following the Lehman crash, there is a drop in the correlations that lasts until the beginning of 2009 . Also in this case, the linkages between markets enhance the tendency of the assets to move together.

In order to gather some understanding on the transmission of shocks, Figure 5 reports the means of the distributions of volatility impulse responses following a one-standard deviation shock. The returns of gold are stable, in the sense that the marginal change of their uncertainty is not substantially affected by the turmoil. The reaction of the variance of the bilateral exchange rates is, instead, magnified. Figure 5 also shows that the price gold and the bilateral exchange rates tend to decouple, as the response of the covariance on impact falls for the turmoil period.

There are two issues with this type introductory evidence. We are looking at the mean of the distribution of volatility impulse responses. There can be relevant information that is carried over in the relation between gold and foreign exchange rates at the tail of the distribution. The second aspect concerns the lack of a criterion of statistical significant of the figures discussed earlier. Both these issues are addressed in the next section, where we consider a framework for testing how the relation between gold and foreign exchange rates 
has changed after the turmoil.

\section{A look at the tails}

Standard tests for comovements rely on the estimation of correlations between asset returns. These tests are however typically significant both to the presence of heteroskedasticity, and to departures from normality in the empirical distributions of two returns. The comovement box of Cappiello, Gerard and Manganelli (2005) relies on semiparametric methods to provide a robust method for analyzing comovements.

Let $\left\{r_{i, t}\right\}_{t=1}^{T}$ and $\left\{r_{j, t}\right\}_{t=1}^{T}$ denote the time series of returns on two different maturities of crude oil futures. Define by $q_{\theta, i}^{r_{i}}$ the $\theta$-quantile of the conditional distribution of $r_{i, t}$ at time t. $F_{t}\left(r_{i}, r_{j}\right)$ denotes the conditional cumulative joint distribution of the two asset returns. Finally,

$$
\begin{aligned}
& F_{t}^{-}\left(r_{i} \mid r_{j}\right):=\operatorname{prob}\left(r_{i, t} \leq r_{i} \mid r_{j, t} \leq r_{j}\right) \\
& F_{t}^{+}\left(r_{i} \mid r_{j}\right):=\operatorname{prob}\left(r_{i, t} \geq r_{i} \mid r_{j, t} \geq r_{j}\right)
\end{aligned}
$$

The conditional probability

$$
p_{t}(\theta):= \begin{cases}F_{t}^{-}\left(q_{\theta, t}^{r_{i}} \mid q_{\theta, t}^{r_{j}}\right) & \text { if } \theta \leq 0.5 \\ F_{t}^{+}\left(q_{\theta, t}^{r_{i}} \mid q_{\theta, t}^{r_{j}}\right) & \text { if } \theta>0.5 .\end{cases}
$$

can be used to represent the characteristics of $F_{t}\left(r_{i}, r_{j}\right)$. In fact, $p_{t}(\theta)$ measures the probability that the returns at maturity $i$ are below its $\theta$-quantile, conditional on the same event occurring at maturity $j$.

The information about $p_{t}(\theta)$ is summarized in the so-called 'comovement box'. This is a square with unit size where $p_{t}(\theta)$ is plotted against $\theta$. Since the shape of $p_{t}(\theta)$ depends on the joint distribution of the two time series, it can be derived only by numerical simulation.

The framework of Cappiello, Gerard and Manganelli (2005) can also be used to test whether the dependence between two markets has changed over time. Given a cutoff date of a specific event, we can can estimate the conditional probability of comovements in two different periods, and plot the estimated probabilities in a graph. Differences in the intensity of comovements can then be detected. This idea can be formalized in a simple way. Denote by $p^{A}(\theta):=A^{-1} \sum_{t<\tau} p_{t}(\theta)$ and $p^{B}(\theta):=B^{-1} \sum_{t<\tau} p_{t}(\theta)$ the average conditional probabilities before and after a certain event occurs at a threshold $\tau$, with $A$ and $B$ the number of corresponding observations. Let $\Delta(\underline{\theta}, \bar{\theta})$ denote the area between $p^{A}(\theta)$ and $p^{B}(\theta)$. A measure of contagion or spillovers between the two markets can be introduced by noting that contagion increases if

$$
\Delta(\underline{\theta}, \bar{\theta})=\int_{\underline{\theta}}^{\bar{\theta}}\left[p^{B}(\theta)-p^{A}(\theta)\right] d \theta>0 .
$$


We stress that, unlike the standard measures of correlation, $\Delta(\underline{\theta}, \bar{\theta})$ allows to study changes in co-dependence over specific quantiles of the distribution.

Several steps are followed to construct the comovement box and test for differences in conditional probabilities. First, we estimate univariate time-varying quantiles using the Conditional Autoregressive Value at Risk (CAViaR) model proposed by Engle and Manganelli (2004). For each series and each quantile, we create an indicator variable that takes the value one if the return is lower than this quantile, and zero otherwise. Then we regress the $\theta$-quantile indicator variable on market $j$ on the $\theta$-quantile indicator on market $i$. The estimated regression coefficients provide a measure of conditional probabilities of comovements, and of their changes across regimes.

The time-varying quantiles of the returns are estimated using the CAViaR model of Engle and Manganelli (2004). The quantiles of the returns $r_{t}$ are assumed to follow the autoregressive model

$$
q_{t}\left(\beta_{\theta}\right)=\beta_{\theta, 0}+\sum_{i=1}^{q} \beta_{\theta, i} q_{t-i}+\sum_{i=1}^{p} l\left(\beta_{\theta, j}, r_{t-j}, \Omega_{t}\right),
$$

where $\Omega_{t}$ denotes the information set at time $t$. The autoregressive terms of the quantiles are meant to capture the clustering of volatility that is typical of financial variables. Including a predetermined information set allows instead to consider the interaction between the quantiles and the conditions of the market. Following Cappiello, Gerard and Manganelli (2005), we estimate the time-varying quantiles using the following specification of the CAViaR:

$$
q_{t}\left(\beta_{\theta}\right)=\beta_{\theta, 0}+\beta_{\theta, 1} d_{t}+\beta_{\theta, 2} r_{t-1}+\beta_{\theta, 3} q_{t-1}\left(\beta_{\theta}\right)-\beta_{\theta, 2} \beta_{\theta, 3} r_{t-2}+\beta_{\theta, 4}\left|r_{r-1}\right| .
$$

The dummy variable $d_{t}$ ensures that the periods of high and low volatility have the same proportion of quantile exceedances.

In order to investigate the specification of the CAViaR model, we compute the DQ test of Engle and Manganelli (2004). The null hypothesis of the DQ test consists in the lack of autocorrelation in the exceedances of the quantiles. Figure 6 reports the p-values for 99 conditional quantiles, together with the p-values for unconditional quantiles. The specification with unconditional quantiles is rejected over the entire domain.

Figure 7 plots the estimates of the conditional probabilities of comovements in periods with low and high volatility identified identified through the $10 \%$ criterion, whereas figure 7 displays the results for the $5 \%$ criterion. The comovement boxes depict the entire distribution of the returns. There are confidence bands of plus/minus twice the standard errors around the estimates of the probabilities of comovements.

Two observations emerge. The first one is that the tails of the distributions carry relevant information on the relation between the variables. In particular, the relation between the probabilities of comovement before and after the turmoil changes across the domain, since 
the relative position of the two curves varies. The second point of interest is that, given the uncertainty in the estimates, the change in the probability of comovement after the turmoil is not statistically-significant with respect to the pre-turmoil period. Thus, the transmission mechanism of shocks between the bilateral exchange rates and the price of gold is not affected by the turmoil.

Table 3 reports the results of the test for contagion outlined earlier for two parts of the distributions. All the test statistics have a positive sign, indicating an increase in comovement after the turmoil on average. However, the null hypothesis is rejected strongly in all the cases. These findings uncover an important source of the stability generated by gold. In this paper we stress the ability to shield portfolios from the effects of spillovers with U.S. Dollar exchange rates, regardless how extreme market conditions are.

\section{Conclusion}

The relation between gold prices and the U.S. Dollar exchange rate has been subject to intense scrutiny. In particular, a significant body of literature attributes a value to gold of safe haven or hedging capabilities against exchange rate fluctuations. Numerous commentators have suggested that the beneficial properties of gold have survived the recent turmoil in financial markets. In this paper, we study the impact of the turmoil on two sources of these properties. We consider the evolution of the pattern of volatility spillovers between gold prices and the Dollar. We investigate whether the turmoil has determined an increase in contagion, defined as the probability of extreme tail events in both gold prices and the Dollar. Our results suggest that gold generates stable comovements with the Dollar that have indeed persisted during the recent phases of market disruption. We also show that exogenous volatility shocks tend to generate reactions of gold prices that are more stable than those of the U.S. Dollar.

To our knowledge, this is the first contribution that discusses the structural features of volatility transmission in the gold market. The relevant question concerns the nature of the determinants of the changes in contagion. For instance, it would be important to understand how deep the relation between gold prices and the U.S. Dollar is around the business cycle. We can also consider the issue of whether the properties of gold discussed earlier arise also in the relation with other asset classes. We might expect U.S. stocks to represent a relevant candidate. The available literature has not yet quantified the advantages of gold holdings in a systematic framework of portfolio allocation. In this sense, it would be interesting to compute the implications for standard risk measures, such as the Value-at-Risk. Finally other types of multivariate models of tail behaviour could be used. In a related work-in-progress, we consider bivariate copulas to model the joint determinants of co-exceedances. 


\section{References}

Baur, D. G., and B. M. Lucey (2010), "Is Gold a Hedge or a Safe Haven? An Analysis of Stocks, Bonds and Gold", The Financial Review, 5(3), 217-229.

Baur, D. G., and T. K. McDermott (2010), "Is Gold a Safe Haven? International Evidence", Forthcoming, Journal of Banking and Finance.

Blose, L. E. (2010), "Gold Prices, Cost of Carry, and Expected Inflation", Journal of Economics and Business, 62(1), 35-47.

Cappie, F., T. C. Mills, and G. Wood (2005), "Gold as a Hedge against the Dollar", Journal of Internation Financial Markets, Institutions and Money, 15, 343-352.

Cappiello, L., B. Gerard, and S. Manganelli (2005), "Measuring Comovements by Regression Quantiles," ECB Working Paper 501.

Christie-David, R., M. Chaudhry, and T. W. Koch (2000), "Do Macroeconomics News Releases Affect Gold and Silver Prices", Journal of Economics and Business, 52(5), 405-421.

Davidson, S., R. Faff, and D. Hillier (2003), "Gold Factor Exposures in International Asset Pricing", Journal of Internation Financial Markets, Institutions and Money, 13, 271-289.

Engle, R. F., and F. K. Kroner (1995), "Multivariate Simultaneous Generalized ARCH", Econometric Theory, 11, 122-150.

Engle, R., and S. Manganelli (2004), "CAViaR: Conditional Autoregressive Value at Risk by Regression Quantiles," Journal of Business and Economic Statistics, 22, 367-381.

Forbes, K. J., and R. Rigobon (2002), "No Contagion, Only Interdependence: Measuring Stock Market Comovements," Journal of Finance, 57, 2223-2261.

Hafner, C. M., and H. Herwartz (2006), "Volatility Impulse Responses for Multivariate GARCH Models: An Exchange Rate Illustration," Journal of International Money and Finance, 25(5), 719-740.

Rigobon, R. (2003), "Identification through Heteroskedasticity," Review of Economics and Statistics, 85(4), 777-792.

Rigobon, R., and B. Sack (2003), "Measuring the Reaction of Monetary Policy to the Stock Market," Quarterly Journal of Economics, 118(2), 639-669.

Sjaastad, L. A., and F. Scacciavillani (2003), "The Price of Gold and the Exchange Rate," Journal of International Money and Finance, 15(6), 879-897.

Spargoli, F., and P. Zagaglia (2008), "The Comovements Along the Forward Curve of Natural Gas Futures: A Structural View," Journal of Energy Markets, 1(3), 23-47.

Wright, P. (1928), The Tariff on Animal and Vegetable Oils, The institute of Economics, The Macmillan Company, New York. 
Table 1: Descriptive statistics of prices (in logarithm)

\begin{tabular}{lccccccccc}
\hline & \multicolumn{4}{c}{ Before the turmoil } & \multicolumn{5}{c}{ During the turmoil } \\
\cline { 2 - 9 } & Mean & St. dev. & Skewness & Kurtosis & Mean & St. dev. & Skewness & Kurtosis \\
\cline { 2 - 9 } Gold & 6.2892 & 0.1816 & -0.1496 & 1.3521 & 6.8009 & 0.1287 & -0.1694 & 2.8837 \\
USD/EUR & 0.2408 & 0.0431 & -0.1306 & 1.9724 & 0.3552 & 0.0620 & -0.2055 & 2.3236 \\
USD/GBP & 0.6235 & 0.0456 & -0.0248 & 2.0072 & 0.5548 & 0.1258 & -0.0929 & 1.5509 \\
\hline
\end{tabular}


Table 2: Parameter estimates of the structural BEKK

\begin{tabular}{lcccc}
\hline & \multicolumn{3}{c}{ USD /GBP - Gold } \\
\cline { 2 - 5 } Parameter & Point estimate & $t$ stat. & Point estimate & $t$ stat. \\
\hline & & & & \\
$c_{1,1}$ & 0.2908 & 3.6784 & 0.2908 & 2.7094 \\
$c_{1,2}$ & 1.0144 & 12.8313 & 0.3608 & 1.5084 \\
$c_{2,2}$ & 2.1310 & 26.9553 & 2.6808 & 3.5785 \\
& & & & \\
$a_{1,2}$ & -4.2570 & -53.8473 & 2.8468 & 2.0312 \\
$a_{2,1}$ & 2.8960 & 36.6318 & 1.8961 & 7.6318 \\
& & & & \\
$g_{1,1}$ & 0.8438 & 10.6733 & -0.7600 & 9.0153 \\
$g_{1,2}$ & -0.2194 & -2.7752 & 0.7600 & 2.4137 \\
$g_{2,1}$ & -0.1291 & -1.6330 & 0.7600 & 6.2190 \\
$g_{2,2}$ & 0.7600 & 9.6133 & -0.7600 & 4.6201 \\
& & & & \\
$t_{1,1}$ & 0.4715 & 5.9641 & 0.6100 & 3.4309 \\
$t_{1,2}$ & 0.2745 & 3.4722 & 0.7745 & 6.0121 \\
$t_{2,1}$ & 0.2399 & 3.0345 & 0.2935 & 4.0922 \\
$t_{2,2}$ & 0.3840 & 4.8573 & 0.5945 & 4.8022 \\
& & & & \\
\hline
\end{tabular}


Table 3: Test of difference in tail co-incidences between periods before and during the turmoil

\begin{tabular}{lcccc}
\hline & \multicolumn{2}{c}{ Lower tail: $\theta \leq 0.5$} & \multicolumn{2}{c}{ Higher tail: $\theta \geq 0.5$} \\
\cline { 2 - 5 } & \multicolumn{2}{c}{$\hat{\delta}(0,0.5)$} & \multicolumn{2}{c}{$\hat{\delta}(0.5,1)$} \\
& Stat. & s.e. & Stat. & s.e. \\
\hline USD/EUR - Gold & -1.7555 & 2.1640 & -0.4084 & 2.5282 \\
USD/GBP - Gold & -2.2261 & 2.7650 & -1.0981 & 2.3332 \\
\hline
\end{tabular}


Figure 1: Data series
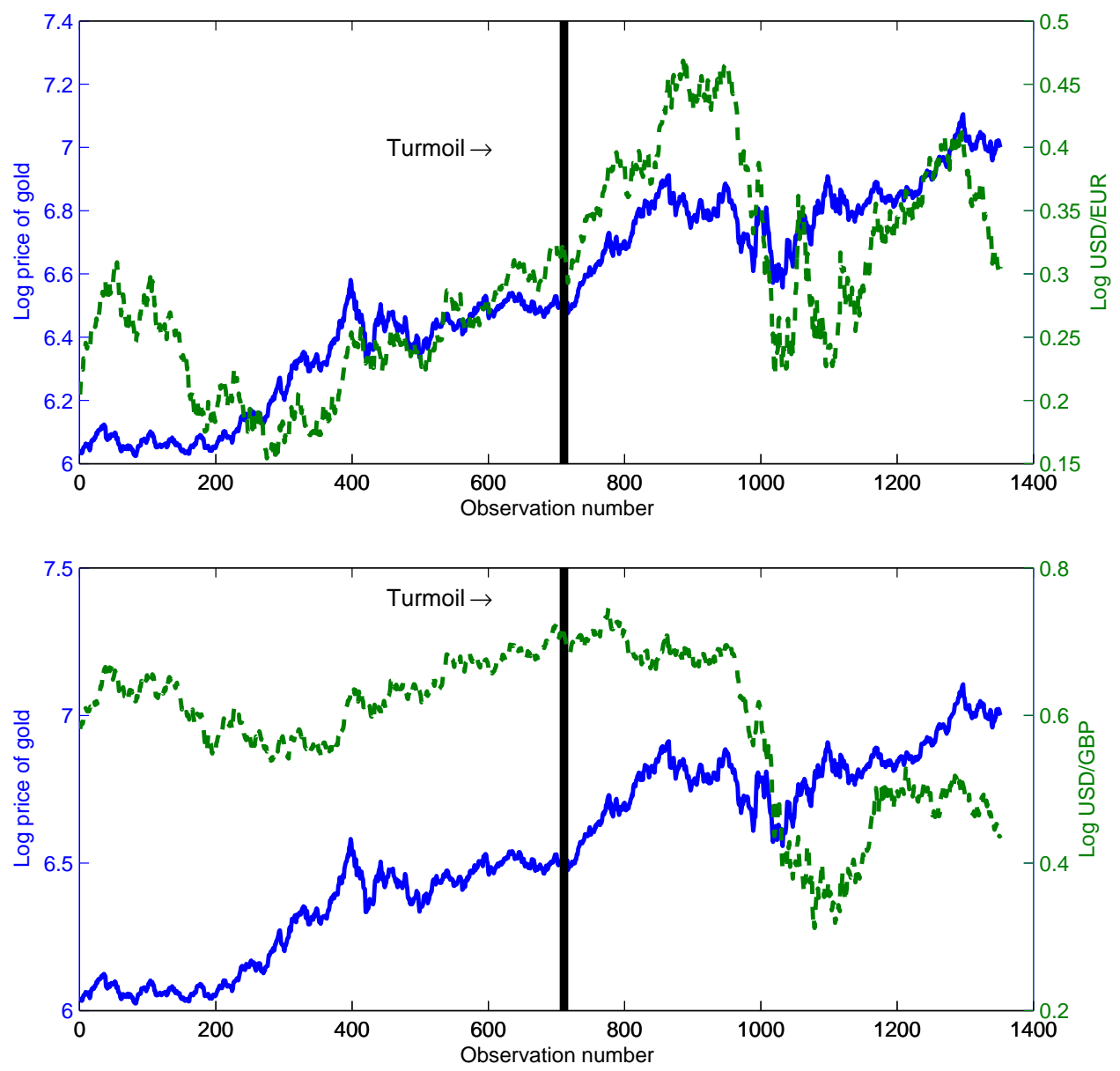
Figure 2: Scatter plots
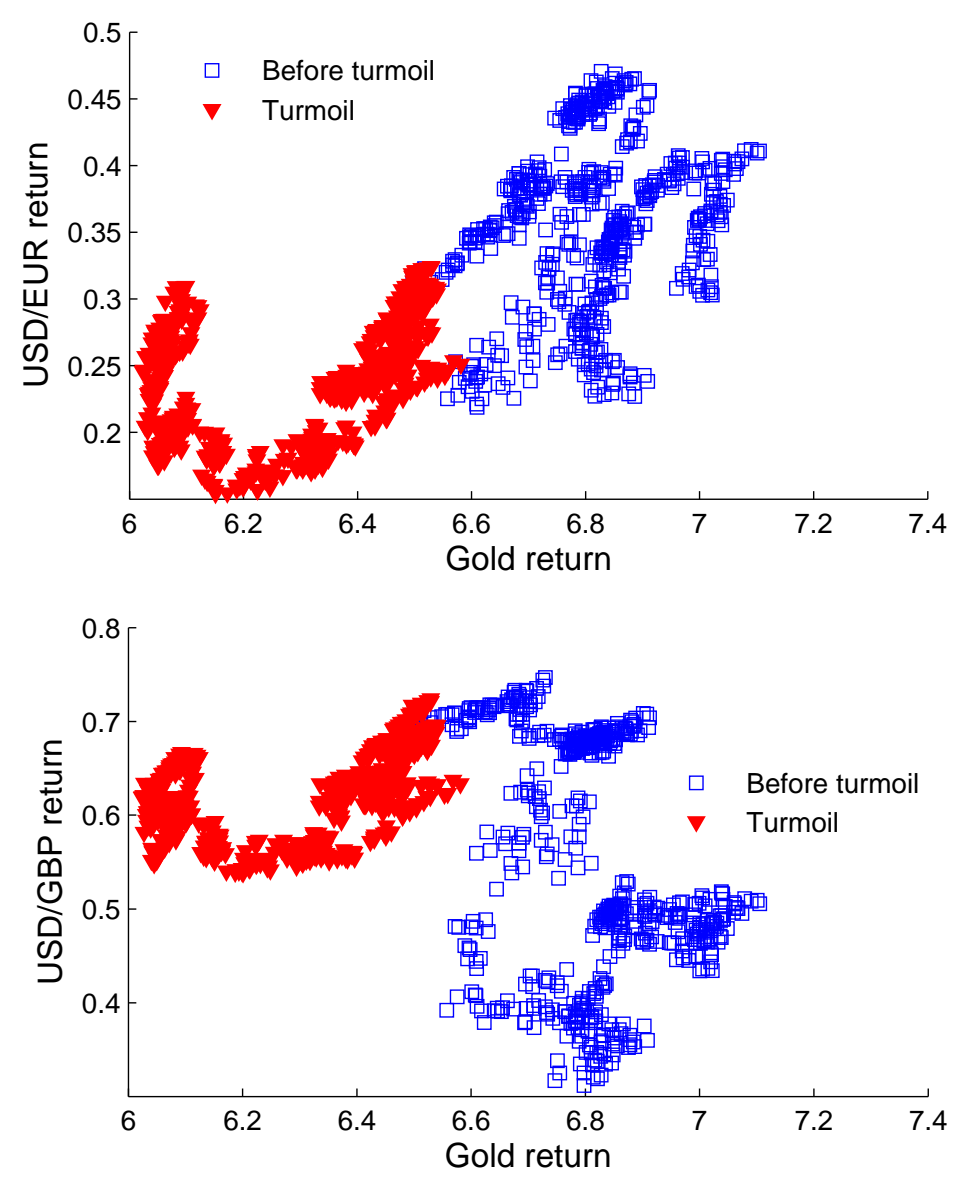

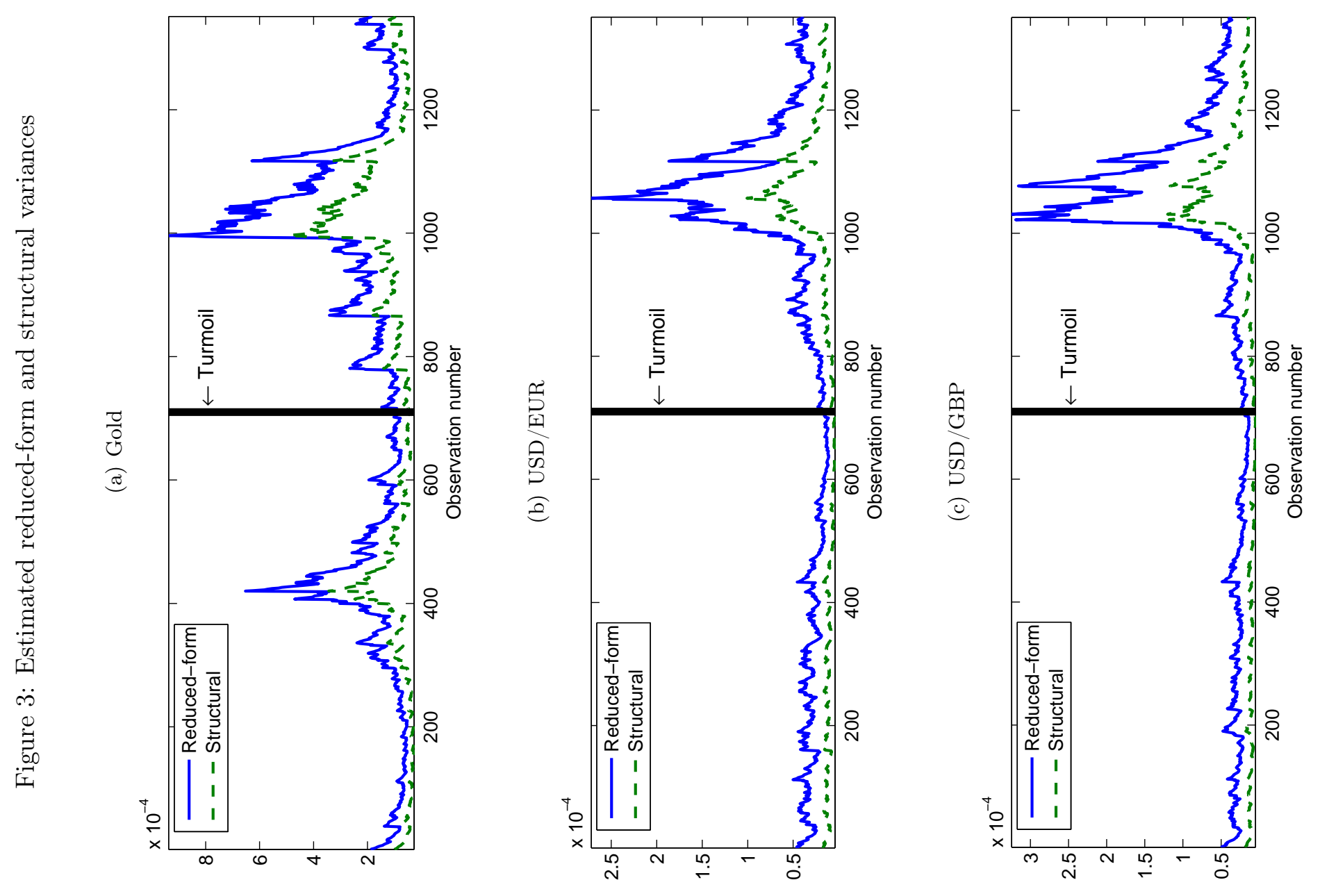
Figure 4: Estimated reduced-form and structural correlations

(a) USD/EUR - gold

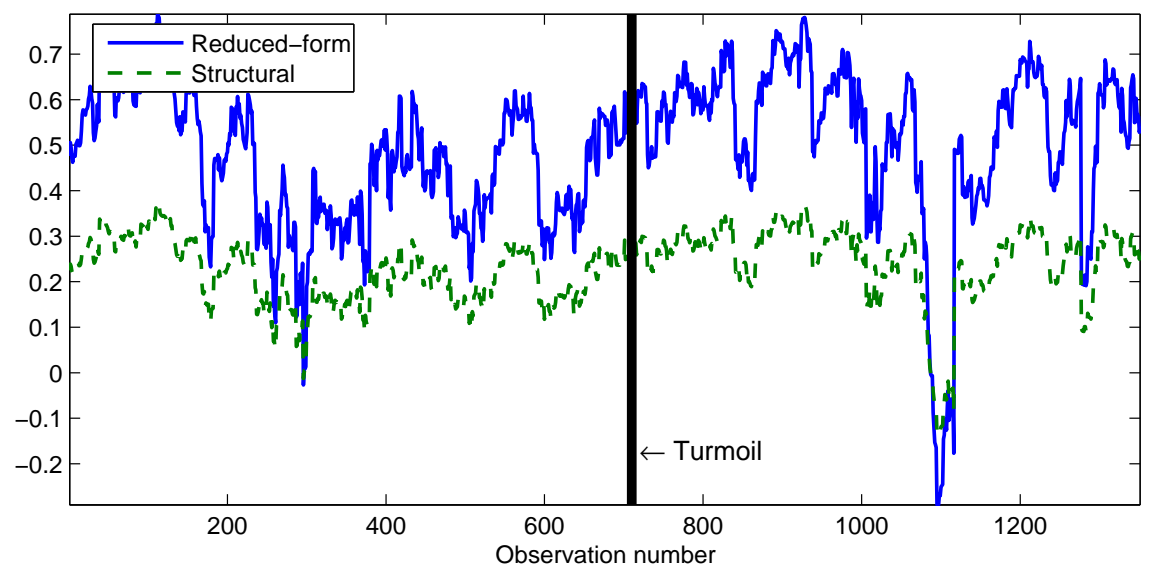

(b) USD /GBP - gold

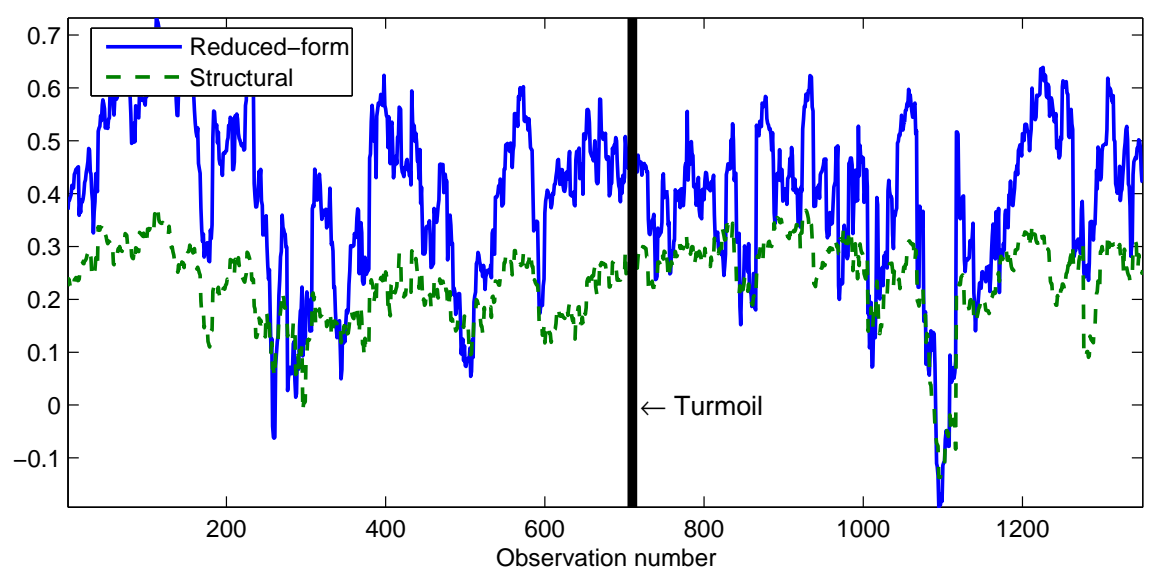




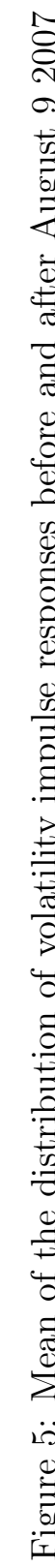

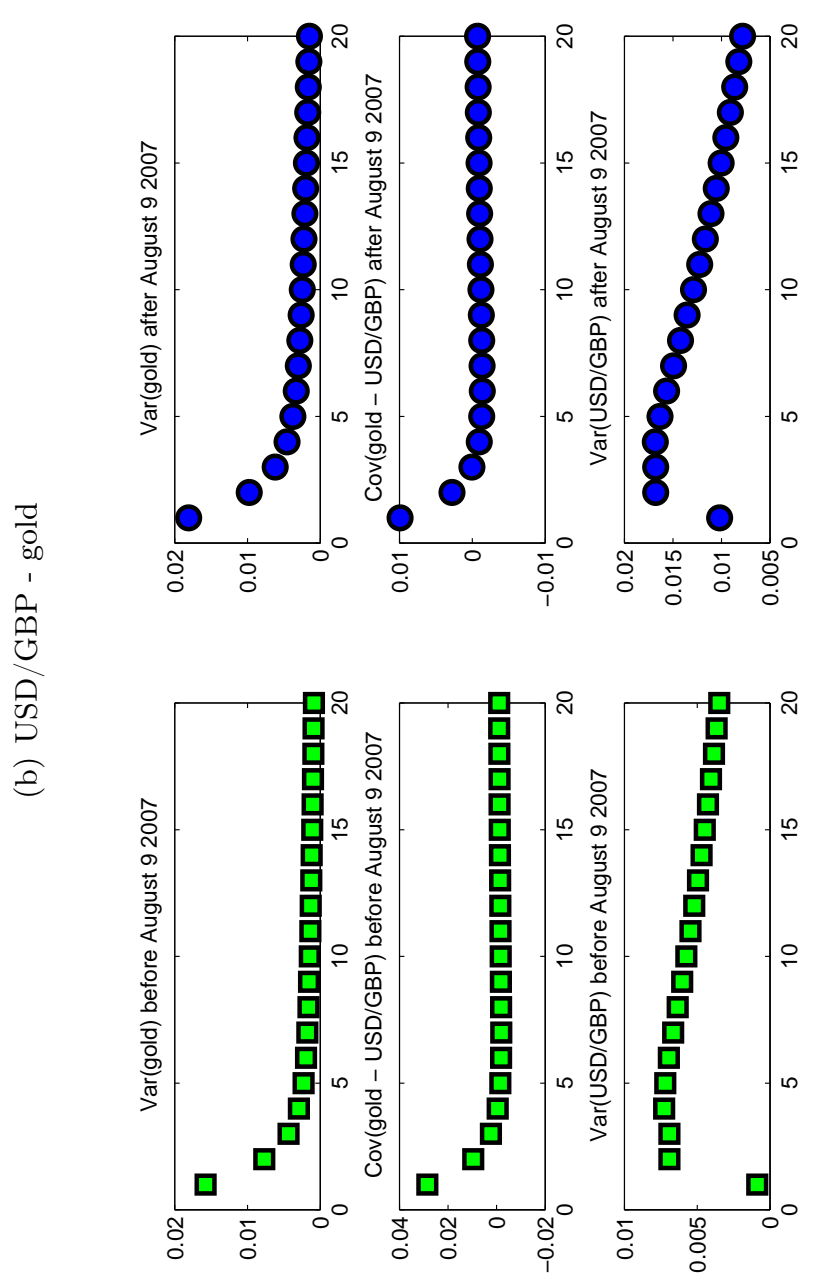


Figure 6: $p$-values of the dynamic quantile test

(a) USD/EUR - gold

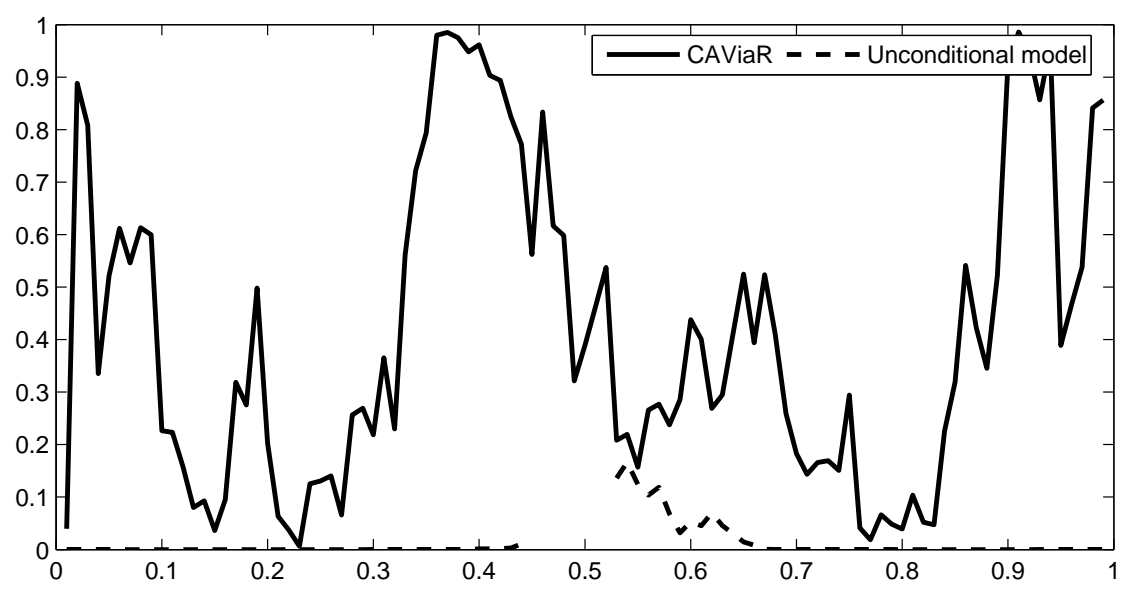

(b) USD/GBP - gold

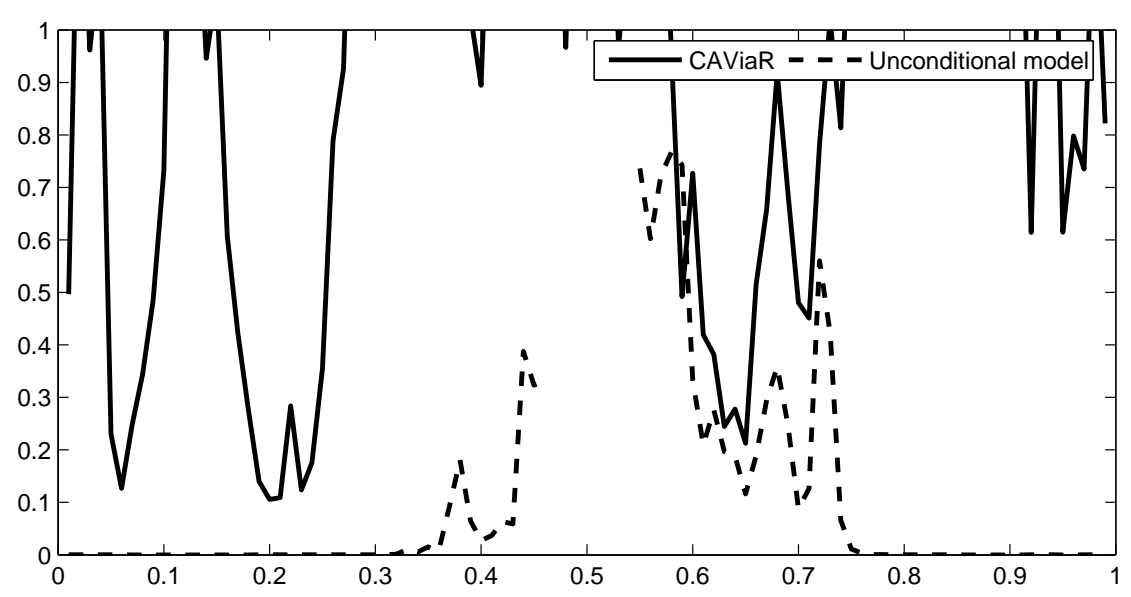


Figure 7: Estimated tail co-dependence
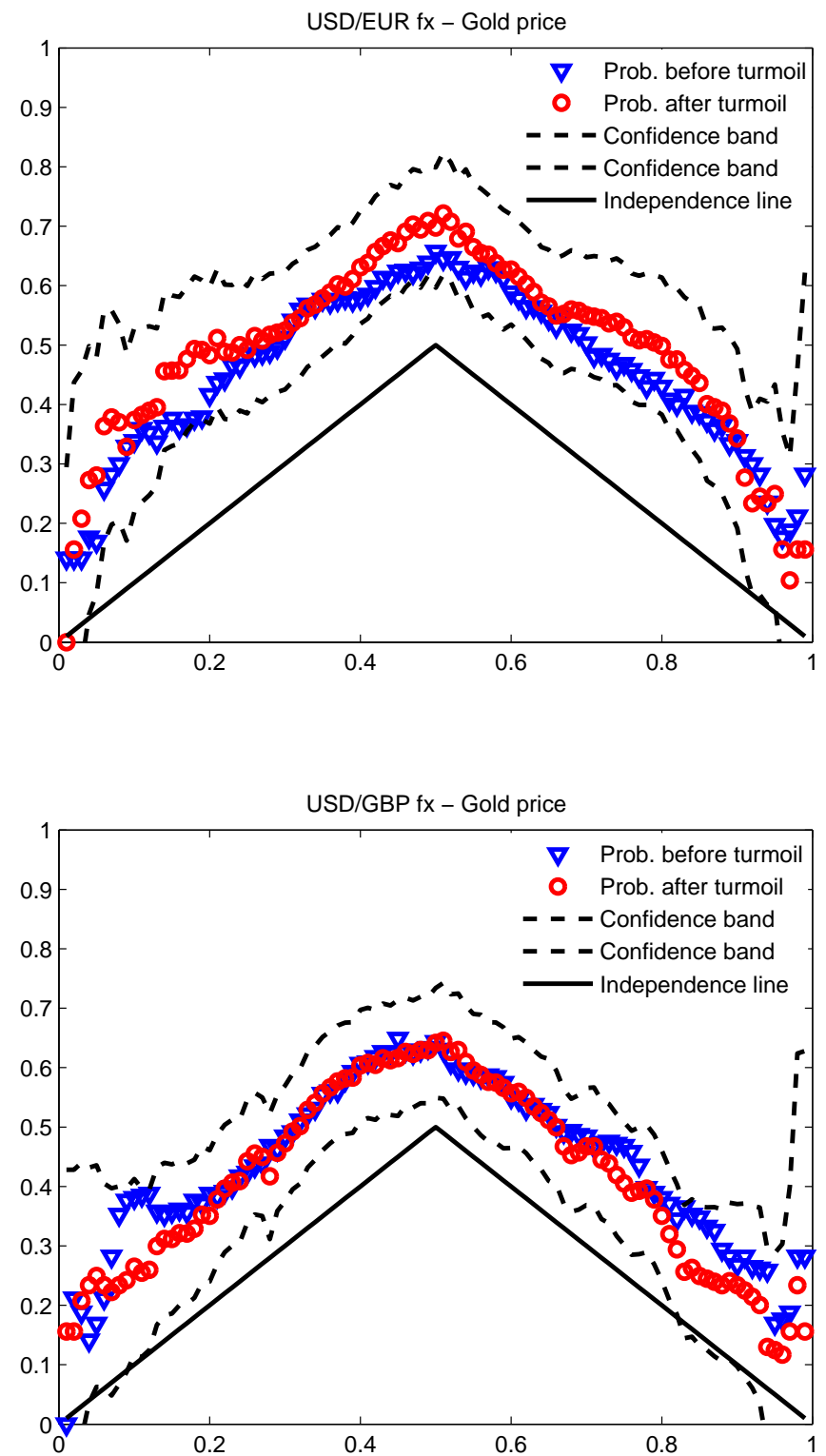